\title{
Dawning of a new lung age?
}

See linked article by Newbury et al. on pg 78

\section{*Brendan Cooper ${ }^{\mathrm{a}}$}

a Consultant Clinical Scientist, Department of Lung Investigation, Queen Elizabeth Hospital, Birmingham, UK

*Correspondence:

Dr Brendan Cooper, Lung Function and Sleep (Office 2), Lung Investigation - University Hospitals Birmingham NHS Foundation Trust, Queen Elizabeth Hospital Birmingham, Mindelson Way, Edgbaston, Birmingham, B15 2WB, UK Tel: +44 (0)1213713890 Fax: +44 (0)121 4605822 E-mail: Brendan.Cooper@uhb.nhs.uk

The search for the elusive "golden bullet" index to capture the degree of lung damage caused by smoking in patients has eluded respiratory medicine throughout its modern history. The usurpers of the forced expiratory volume in one second $\left(\mathrm{FEV}_{1}\right)$ lower limit of normal $-\mathrm{FEV}_{1} \%$ predicted, the $\mathrm{FEV}_{1} /$ forced vital capacity (FVC) ratio, FEV6, lung age and maximum mid-expiratory flow have all failed to capture the change in the normal lung function trajectory predicted by Fletcher and Peto. 'The popular "lung age" index on the face of it appears simple to use, persuasive, and easy to explain to the average patient, and it has a resonance with most general practitioners (GPs). However, scientific scrutiny and evidence has continually undermined this "assassin" of quality diagnostic spirometry.

In this issue of the PCRJ, Newbury et al. ${ }^{2}$ reinvestigate the limitations of the lung age index in a well designed and clear study comparing the lung age equations that have been published over several decades. Their findings uncover the discrepancies in lung age and chronological age which they suggest is caused by the different populations studied or changes in technology and standards.

Lung age is the retrospective calculation of predicted and actual spirometry values from reference values using sex, height and age, to determine the theoretical age of the patient based on their actual lung function. Unfortunately, it simplifies the factors that affect lung deterioration into a single parameter only - age. Clearly, this is a gross oversimplification of why lung function changes with age and disease. The original use of lung age was popularised by Morris \& Temple in $1985,{ }^{3}$ but as always with predictive equations, its calculation inevitably depends on a representative and reliable reference population. However, this has consistently proved to be the weak link in the use of all lung age reference equations and their derivatives to date.

Errors of the lung age approach include the lack of a continuing rise in airflow obstruction after 60 years of age, and the large overlap in midlife lung ages (30-50 years) when the persuasiveness of smoking effects needs to be larger. ${ }^{4}$ Others ${ }^{5}$ have previously outlined the problems with the Morris values - which use a mean lung age without any scatter of values that immediately introduces errors of either under- or over-estimated lung age. Others have used lung age in smokers but only when it is less than chronological age - which is both ethically unsound and scientifically illogical.

There is little evidence for physiological impairment influencing behavioural change and encouraging patients to quit smoking. Spirometry as a motivating tool for smoking cessation is therefore of limited value. Most concerning is that the abstinence from smoking is actually no better when patients are confronted with observable changes in their lung function. ${ }^{8}$ Parkes et al. ${ }^{9}$ showed that using lung age to persuade smokers to quit increased quit rates from $6.4 \%$ to $13.6 \%$ (both pitiful levels of smoking cessation rates), but also showed that people with a worse lung age are no more likely to quit - so the mechanism for smoking cessation using spirometry remains unclear.

The explanation given for the discrepancies in lung age versus chronological age in this current paper ${ }^{2}$ include the improvement in technology and standards of spirometry which is in part born out by several publications. ${ }^{10,11}$ However, errors in absolute measurement in spirometers would affect both smokers and non-smokers equally. The authors' other suggestion that this shift in pattern is caused by the different populations studied is more credible, but using a single lung age equation in global populations is not rational.

Newbury et al.'s conclusion that predictive equations need regular updating is very timely, since a new lung age is dawning with the first results of the Multi-ethnic reference values for spirometry ERS Task Force ${ }^{12}$ due to produce new global reference ranges very soon. Nevertheless, whilst it may appear that these new reference values could be used to improve the reliability of the current lung age estimations for patients, it is the concept of lung age and not the reference values that is flawed.

The aim in diagnostics for COPD is to detect an altered lung function trajectory and intervene with appropriate treatment/ prevention earlier rather than later when irreversible damage has taken hold. This re-visits the points raised by Quanjer and Enright, ${ }^{5}$ that in the end it is the Lower Limit of Normal (LLN) for FEV ${ }_{1}$, and the $\mathrm{FEV}_{1} / \mathrm{FVC}$ ratio, that should be tracked for each individual. Furthermore, the concept of lifetime lung health checks every decade from 25 to $85+$ using quality diagnostic spirometry remains the "golden bullet" to detect abnormal individual lung deterioration. ${ }^{13}$ This Newbury et al. paper, whilst being well argued and provocative, is sadly another false dawn for lung age. The authors are to be congratulated on highlighting the limitations of lung age and reexamining the arguments as to why it should not be adopted widely.

Many in primary care will consider whether it matters that a "rough and ready" index tool like lung age will be useful for COPD screening purposes. In short, it will matter. Any initial apparent gains in smoking cessation will lead ultimately to a long term loss of trust and credibility in primary care advice on smoking cessation. Treating the patient and not the numbers always works best.

Conflicts of interest The author declares that he has no conflicts of interest in relation to this article. 
Commissioned article; not externally peer-reviewed; accepted 10th February 2012; online 29th February 2012

(c) 2012 Primary Care Respiratory Society UK. All rights reserved http://dx.doi.org/10.4104/pcrj.2012.00021

Prim Care Respir J 2012; 21(1): 15-16

\section{References}

1. Fletcher C \& Peto R. The natural history of chronic airways obstruction. BMJ 1977; 1:1645-8. http://dx.doi.org/10.1136/bmj.1.6077.1645

2. Newbury W, Lorimer $M$, Crockett $A$. Newer equations better predict lung age in smokers: a retrospective analysis using a cohort of randomly selected participants. Prim Care Respir J 2012;21:78-84. http://dx. doi.org/10.4104/pcrj.2011.00094

3. Morris J \& Temple W. Spirometric "lung age" estimation for motivating smoking cessation. Prev Med 1985; 14:655-62.

http://dx.doi.org/10.1016/0091-7435(85)90085-4

4. Hansen J, Sun X-G, Wasserman K. Calculating gambling odds and lung ages for smokers. Eur Respir J 2010;35(4):776-80. http://dx.doi.org/10.1183/09031936.00107709

5. Quanjer P H, Enright P L. Editorial: Should we use lung age? Prim Care Respir J 2010;19:400-01.http://dx.doi.org/10.4104/pcri.2010.00045

6. Wilt TJ, Niewoehner D, Kane RL, MacDonald R, Joseph AM. Spirometry as a motivational tool to improve smoking cessation rates: a systematic review of the literature. Nicotine Tob Res 2007;9:21-32. http://dx.doi.org/10.1080/ 14622200601078509

7. Stead LF, Bergson G, Lancaster T. Cochrane Tobacco Addiction Group. Published Online: 8 OCT 2008. Assessed as up-to-date: 13 FEB 2008 http://dx.doi.org/10.1002/14651858.CD000165.pub3

8. Kotz D, Wesseling G, Huibers MJH van Schayck OCP. Efficacy of confronting smokers with airflow limitation for smoking cessation. Eur Respir J 2009;33(4): 754-62. http://dx.doi.org/10.1183/09031936.00116308

9. Parkes $G$, Greenhalgh T Griffin M, Dent R. Effect on smoking quit rate or telling patients their lung age: the Step2Quit randomised controlled trial. BMJ 2008;336: 598-600. http://dx.doi.org/10.1136/bmj.39503.582396.25

10. Nelson, SB, Gardner RM, Crapo RO, Jensen RL. Performance evaluation of contemporary spirometers. Chest 1990;97(2):288-97. http://dx.doi.org/10.1378/ chest.97.2.288

11. Jensen RL, Teeter JG, England RD, et al. Sources of long-term variability in measurements of lung function: implications for interpretation and clinical trial design. Chest 2007;132(2):396-402. http://dx.doi.org/10.1378/chest.06-1999

12. Quanjer PH, Stanojevic S, Tim J. et al. Multi-ethnic reference values for spirometry for the 3-95 year age range: The Global Lung 2012 Initiative. Report of the Global Lungs Initiative, ERS Task Force to establish improved Lung Function Reference Values, endorsed by the ATS, ACCP, ANZSRS, TSANZ and the APSR. (In Press).

13. Sibille $Y$, Decramer $M$, Nicod $L P$, et al. Directing the future of lung health: the European Respiratory Roadmap. Eur Respir J 2011;38(3):502-06. http://dx.doi.org/10.1183/09031936.00097111

Available online at http://www.thepcrj.org 